\title{
Patient with severe fever with thrombocytopenia syndrome virus infection and central nervous system disturbance in Dongyang, Zhejiang Province, China, 2017
}

Yi Sun ${ }^{1+}$, Bin Guo ${ }^{2 \dagger}$, Hao Yan ${ }^{1}$, Ai Lan Wu², Wen Wu Yao ${ }^{1}$, Kang Chen ${ }^{2}$, Jun Hang Pan ${ }^{1}$, Zhao Xia Li Hai Yan Mao ${ }^{1}$ and Yan Jun Zhang ${ }^{1 *}$ (D)

\begin{abstract}
Background: Severe fever with thrombocytopenia syndrome (SFTS) is an emerging hemorrhagic fever that was first described in China in 2011. We report a patient who died of Severe fever with thrombocytopenia syndrome virus (SFTSV) infection, with a rapidly progressive central nervous system (CNS) disturbance, in Dongyang, Zhejiang Province, China, in 2017.

Case presentation: A 64-year-old man was admitted to hospital after 4 days of fever. SFTSV was detected 1 day after the patient was admitted to hospital. The patient presented with CNS disturbance and died 4 days after admission. Detailed clinical and epidemiological investigations and laboratory tests were conducted. Reduced platelet, white blood cell, lymphocyte, and neutrophil counts, elevated lactate dehydrogenase, creatine kinase, aspartate aminotransferaseand alanine aminotransferase concentrations, and an increased activated partial thromboplastin time were observed. In a phylogenetic analysis, the isolate clustered close to a strain derived from South Korea.

Conclusions: This is the first case of SFTSV infection with CNS disturbance in Dongyang, Zhejiang Province, China. The surveillance of suspected cases of SFTS is important in SFTSV endemic regions.
\end{abstract}

Keywords: Severe fever with thrombocytopenia syndrome virus, Central nervous system disturbance, Clinical characteristic, Epidemiological feature, Phylogenetic

\section{Background}

Severe fever with thrombocytopenia syndrome virus (SFTSV) poses serious public health concerns globally because it causes tick-borne hemorrhagic fever with a high case fatality rate $(12-50 \%)[1-3]$. Many cases of SFTSV infection have been confirmed in Zhejiang Province, China, since its first comprehensive description in 2011 $[1,4]$. Fever, thrombocytopenia, leukocytopenia, and multi-organ dysfunction have been reported in SFTSVinfected patients. Several studies have reported patients who presented with rapidly progressive disturbances of the central nervous system (CNS), such as a human-

\footnotetext{
* Correspondence: yjzhang@cdc.zj.cn

${ }^{\dagger}$ Yi Sun and Bin Guo contributed equally to this work.

'Zhejiang Provincial Center for Disease Control and Prevention, 3399

Binsheng Road, Hangzhou 310051, Zhejiang, China

Full list of author information is available at the end of the article
}

encephalitis-like syndrome [5-7]. Here, we report a random case of SFTSV infection presenting with humanencephalitis-like syndrome in 2017. To the best of our knowledge, this is the first case of SFTS with CNS involvement reported in Zhejiang Province, China. Our objectives were to understand (1) the clinical human-encephalitislike syndrome and the epidemiological and virological characteristics of this case; (2) the importance of the surveillance of suspected cases of SFTS in SFTSV endemic regions.

The SFTS diagnoses were confirmed based on previously described criteria [4]. Clinically diagnosed encephalitis was defined as a condition meeting the following criteria: (a) sudden onset; (b) symptoms of fever, headache, vomiting, etc.; and (c) disorders of consciousness, which have been previously described $[6,8]$. Serum

(c) The Author(s). 2019 Open Access This article is distributed under the terms of the Creative Commons Attribution 4.0 International License (http://creativecommons.org/licenses/by/4.0/), which permits unrestricted use, distribution, and reproduction in any medium, provided you give appropriate credit to the original author(s) and the source, provide a link to the Creative Commons license, and indicate if changes were made. The Creative Commons Public Domain Dedication waiver (http://creativecommons.org/publicdomain/zero/1.0/) applies to the data made available in this article, unless otherwise stated. 
samples were collected with the permission of the patient and his wife. Blood samples were collected continuously from the patient during his hospitalization for hematological and biochemical examination, to closely monitor the clinical progression of the disease. The samples were stored in 3-5 mL of Hanks solution containing $100 \mathrm{U} / \mathrm{mL}$ penicillin and $100 \mu \mathrm{g} / \mathrm{mL}$ streptomycin, at $-70{ }^{\circ} \mathrm{Cuntil}$ analysis. With the permission of the local government, one tick sample was collected from a hill that the patient had visited, using the flagging and dragging method. The tick was delivered to the local Center for Disease Control and Prevention (CDC) and tested for SFTSV.

Viral RNA was extracted with the RNeasy Mini Kit (Qiagen, Redwood City, CA, USA), according to the manufacturer's instructions. Multiplex Real-time RT-PCR reactions and sequencing of SFTSV were performed as described previously [9]. We constructed multiple alignments with Geneious 11.1.5 (www.geneious.com) using data matrices of SFTSV sequences downloaded from GenBank, according to previous studies [10-12]. Datasetspecific models were selected with the Akaike information criterion in Modeltest 3.7 [13]. A phylogenetic analysis was performed with the general time reversible model as the model of nucleotide substitution and the maximum likelihood (ML) method, and phylogenetic trees based on the different viral segments were constructed with MEGA 7.0.14 (http://www.megasoftware.net/). Segments from Uukuniemi virus (GenBank accession numbers: L, D10759; M, NC_005220; S, NC_005221) were used as outgroups in each segment tree correspondingly. The statistical significance of the constructed phylogenies was estimated with a bootstrap analysis with 1000 pseudoreplicate datasets. The viral sequences from this patient (CMX/Zhejiang/2017) were deposited in GenBank (MK424388-MK424390). Homologous mosaic structures were detected with the Recombination Detection Program v3.29 [14].

\section{Case presentation}

On December 8, 2017, a 64-year-old male retired country doctor who lived in a hilly rural area in Dongyang, Zhejiang Province, China, developed chills, fever, headache, malaise, muscular soreness, nausea, and subconjunctival hemorrhage. He had been healthy up to that point, with no significant underlying illness. He went to a health clinic in town with a temperature of $38.5^{\circ} \mathrm{C}$ on December 9 and stayed at home to rest on December 10. He remained symptomatic and was transferred to Dongyang People's Hospital on the morning of December 11. The patient was recorded as vomiting once and had a fever of $38.5^{\circ} \mathrm{C}$. His platelet (PLT) count was $82 \times 10^{9} / \mathrm{L}$, white blood cell (WBC) count was $1.9 \times 10^{9} / \mathrm{L}$, neutrophilgranulocyte count was $1.22 \times 10^{9} / \mathrm{L}$, and lymphocyte count was $0.53 \times 10^{9} / \mathrm{L}$ (Table 1 ). He was admitted to hospital at noon on December 11 with a fever of $38.0^{\circ} \mathrm{C}$. His gingiva was bleeding. A rash was present all over his lower abdomen, waist, and groin area. He was diagnosed with suspected SFTS based on his symptoms. SFTSV infection was confirmed by the local CDC with a positive SFTSV RNA test on the afternoon of December 12. The patient's PLT count was $76 \times 10^{9} / \mathrm{L}$, WBC count was $1.13 \times 10^{9} / \mathrm{L}$, neutrophil-granulocyte count was $0.81 \times 10^{9} / \mathrm{L}$, and lymphocyte count was $0.3 \times 10^{9} / \mathrm{L}$ on December 12 (Table 1). Laboratory tests showed elevated lactate dehydrogenase (LDH; $466 \mathrm{U} / \mathrm{L}$ ), creatine kinase (CK; $580 \mathrm{U} /$ $\mathrm{L}$ ), alanine aminotransferase (ALT; $54 \mathrm{U} / \mathrm{L}$ ), and aspartate aminotransferase (AST; $137 \mathrm{U} / \mathrm{L}$ ) (Table 1). His activated partial thromboplastin time (aPTT; $45.6 \mathrm{~s}$ ) was longer than normal (Table 1). The patient received the following treatments: (a) both PLTs and white cells were supplied; (b) immunoglobulin and thymosin were used as immune support; and (c) glycyrrhizin was used as an hepatoprotective agent. The patient's speech was slurred and his condition worsened, with progressive disturbance of consciousness from December 13. His PLT count was $82 \times 10^{9} / \mathrm{L}$, WBC count was $2.02 \times 10^{9} / \mathrm{L}$, neutrophil-granulocyte count was $1.56 \times 10^{9} / \mathrm{L}$, and lymphocyte count was $0.36 \times 10^{9} / \mathrm{L}$ on December 13 (Table 1). Significant disorder of consciousness was apparent on the morning of December 14, with suddenly rigidity of the limbs, convulsions, and gnathospasmus, accompanied by systemic cyanosis, during the night of December 14. The patient was transferred to the intensive care unit with a PLT count of $71 \times 10^{9} / \mathrm{L}$, white cell count of $2.77 \times 10^{9} / \mathrm{L}$, neutrophil-granulocyte count of $1.33 \times 10^{9} / \mathrm{L}$, and lymphocyte count of $1.34 \times 10^{9} / \mathrm{L}$ (Table 1). The patient died on the afternoon of December 15 from septic shock, respiratory failure, lactic acidosis, and SFTSV infection involving CNS disturbance.

An epidemiological investigation revealed that the patient had visited a small hill $5 \mathrm{~km}$ from his home to collect herbs and pick persimmonson December 1 with other people from the same village. From his personal statement, there was no clear history of tick exposure. However, according to his companions, several of them had suffered tick bites when they were hunting and farming on previous occasions. The tick sample collected from the hill was negative for SFTSV nucleic acids. The patient also raised nine chickens, and there were two dogs in his neighborhood. No goats or cows were found in the village. No contacts with a similar syndrome were identified.

A real-time RT-PCR analysis of a serum sample from the patient indicated that the patient was positive for SFTSV nucleic acids, with a cycle threshold (CT) value of 26. Samples from his contacts and the tick were negative. We obtained the partial gene sequences of the $\mathrm{S}(1$, $395 \mathrm{bp}), \mathrm{M}(2,940 \mathrm{bp})$, and $\mathrm{L}(5,245 \mathrm{bp})$ segments of this 
Table 1 Daily laboratory parameters during the whole hospitalization period before the patient died

\begin{tabular}{|c|c|c|c|c|c|c|c|c|c|}
\hline Date & $\begin{array}{l}\text { Platelets }(\times \\
\left.10^{9}\right)\end{array}$ & $\begin{array}{l}\text { White } \\
\text { blood cell } \\
\left(\times 10^{9}\right)\end{array}$ & $\begin{array}{l}\text { Neutrophile } \\
\text { granulocyte } \\
\left(\times 10^{9}\right)\end{array}$ & $\begin{array}{l}\text { Lymphocyte } \\
\left(\times 10^{9}\right)\end{array}$ & $\begin{array}{l}\text { Lactate } \\
\text { dehydrogenase } \\
(\mathrm{U} / \mathrm{L})\end{array}$ & $\begin{array}{l}\text { Creatine } \\
\text { kinase } \\
(\mathrm{U} / \mathrm{L})\end{array}$ & $\begin{array}{l}\text { Activated partial } \\
\text { thromboplastin } \\
\text { time (s) }\end{array}$ & $\begin{array}{l}\text { Aspartate } \\
\text { aminotransferase } \\
(\mathrm{U} / \mathrm{L})\end{array}$ & $\begin{array}{l}\text { Alanine } \\
\text { aminotransferase } \\
(\mathrm{U} / \mathrm{L})\end{array}$ \\
\hline $\begin{array}{l}\text { December } \\
11\end{array}$ & 82 & 1.90 & 1.22 & 0.53 & NA & NA & NA & NA & NA \\
\hline $\begin{array}{l}\text { December } \\
12\end{array}$ & 76 & 1.13 & 0.81 & 0.30 & 466 & 580 & 45.6 & 137 & 54 \\
\hline $\begin{array}{l}\text { December } \\
13\end{array}$ & 82 & 2.02 & 1.56 & 0.36 & 1332 & 2936 & NA & 427 & 120 \\
\hline $\begin{array}{l}\text { December } \\
14\end{array}$ & 71 & 2.77 & 1.33 & 1.34 & NA & NA & 77.9 & 942 & 251 \\
\hline $\begin{array}{l}\text { December } \\
15\end{array}$ & 43 & 1.87 & 1.22 & 0.62 & 3073 & 9771 & 164.9 & 2727 & 806 \\
\hline
\end{tabular}

NA not available

SFTSV isolate. A sequence analysis of SFTSV showed 95.8-96.5\% sequence identity with known SFTSV isolates at the nucleotide level $[10,15]$. This SFTSV isolate had arginine at position 624 in the $M$ glycoprotein segment, which may play a critical role in low-pHdependent cell fusion activity [16]. An extensive phylogenetic analysis demonstrated that the isolate was closely related to stains from South Korea (KAGWH3/ KAGWH6) (Fig. 1). No intragenic recombination event or segmental reassortment between lineages was detected in the isolate.

\section{Discussion and conclusions}

Here, we have reported a patient with SFTSV infection accompanied by CNS disturbance in Dongyang, Zhejiang Province, China, in 2017. Previous studies have shown that bunyaviruses, such as the Rift Valley fever virus, may be neurotropic [10, 17]. SFTSV-associated CNS disturbance has been observed, but little information is available on the clinical manifestations, epidemiology, and characteristics of the virus [6, 18]. A previously study reported the occurrence of encephalitis in 19.1\% of hospitalized SFTS patients, with fatal outcomes in $44.7 \%$ of these patients, based on a large sample collected over a long period [6]. In this study, our patient was confirmed as SFTSV infected, and developed clinically diagnosed encephalitis during hospitalization. The diagnosis was based on its sudden onset, and symptoms such as fever, headache, vomiting, and disordered consciousness. The deterioration of consciousness during the course of SFTS is consistently identified as a major risk factor predicting a fatal outcome [5, 7]. We failed to obtain cerebrospinal fluid (CSF) from this patient because his SFTS progressed so rapidly, although other reports have suggested that the observed disturbance of consciousness is an indirect effect of the cytokine storm triggered by SFTSV infection [19]. Screening for SFTSV in patients with encephalitis of unknown cause should be considered, together with screening for common agents that cause viral encephalitis, such as herpes simplex virus type 1.

This SFTSV-infected patient was characterized by the abrupt onset of his fever, together with respiratory tract and gastrointestinal symptoms, followed by a progressive disease course until his death. Laboratory tests showed decreasing trends in his PLT, WBC, neutrophilgranulocyte, and lymphocyte counts, although they were all slightly elevated after treatment on December 13 . We monitored the patient's elevated serum levels of ALT, AST, LDH, and CK, and his elongated aPTT during his hospitalization. These abnormal laboratory parameters were indicative of the pathological lesions in multiple organs and the altered homeostasis of the coagulation system in this patient [1]. Viral replication and the host immune responses are considered to affect the severity and clinical outcome of SFTS $[6,20]$. Longer aPTT (> $62.6 \mathrm{~s}$ ), higher AST (>288 U/L), or higher blood viral RNA load $\left(>10^{5}\right)$ have been suggested to predict a fatal outcome [21, 22]. Reduced consciousness and abnormal laboratory parameters have high predictive value in identifying patients at greater risk of death. In clinical practice, these indicators could be used to reduce the fatality rate and lessen the extent of CNS injury in survivors.

Previous studies based on the extensive phylogenetic analyses have shown that Zhejiang is one of the major areas to import SFTSV from other parts of China and South Korea along migration pathways [11, 15]. The phylogenetic trees we constructed in this study demonstrated that the isolate analyzed originated in South Korea, and differed from isolates derived from mainland of China, including in Shandong, Jiangsu, and Anhui Provinces [23]. SFTS is prevalent in Zhejiang Province, especially between May and August among elderly people living in hilly areas [4]. Our previous seroprevalence study showed that the overall seroprevalence of SFTSV was $7.2 \%$ among 986 healthy individuals who reported no symptoms associated with SFTS in the Pujiang district, which is less than $60 \mathrm{~km}$ from Dongyang 


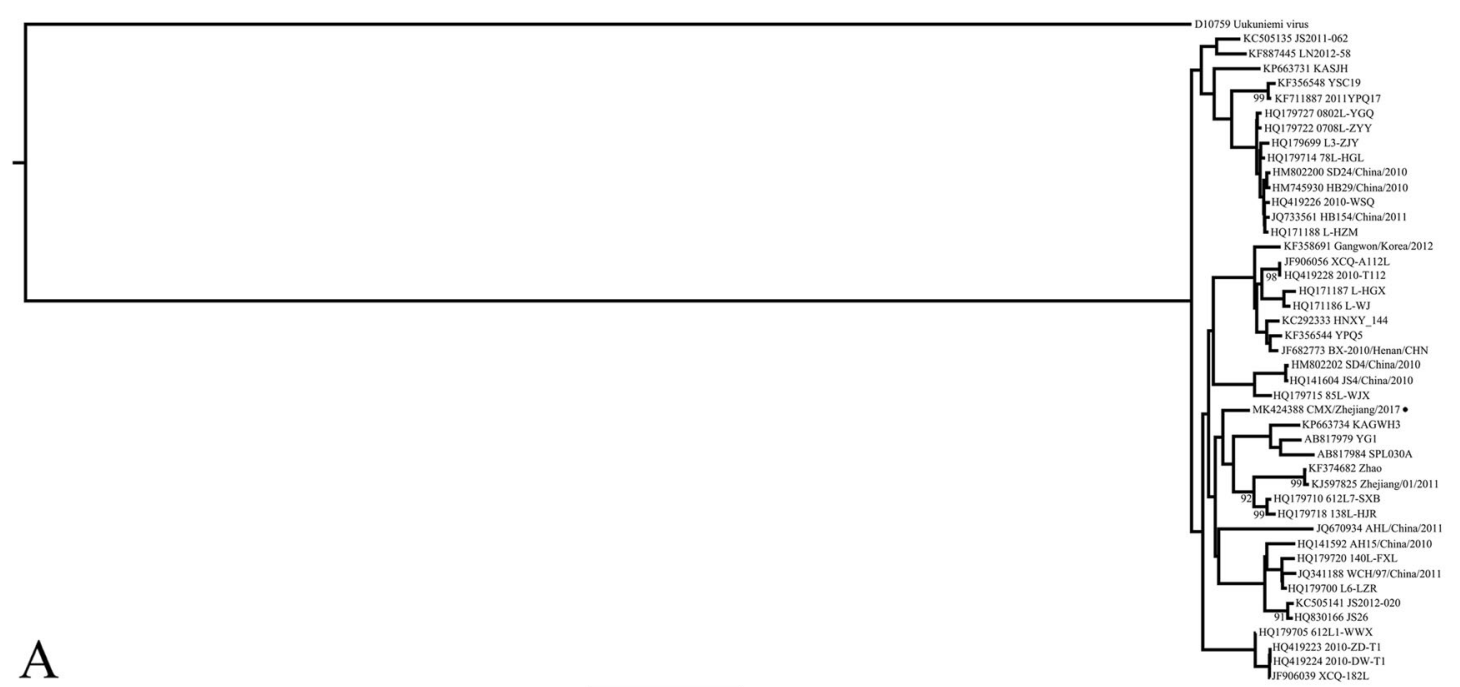

0.04
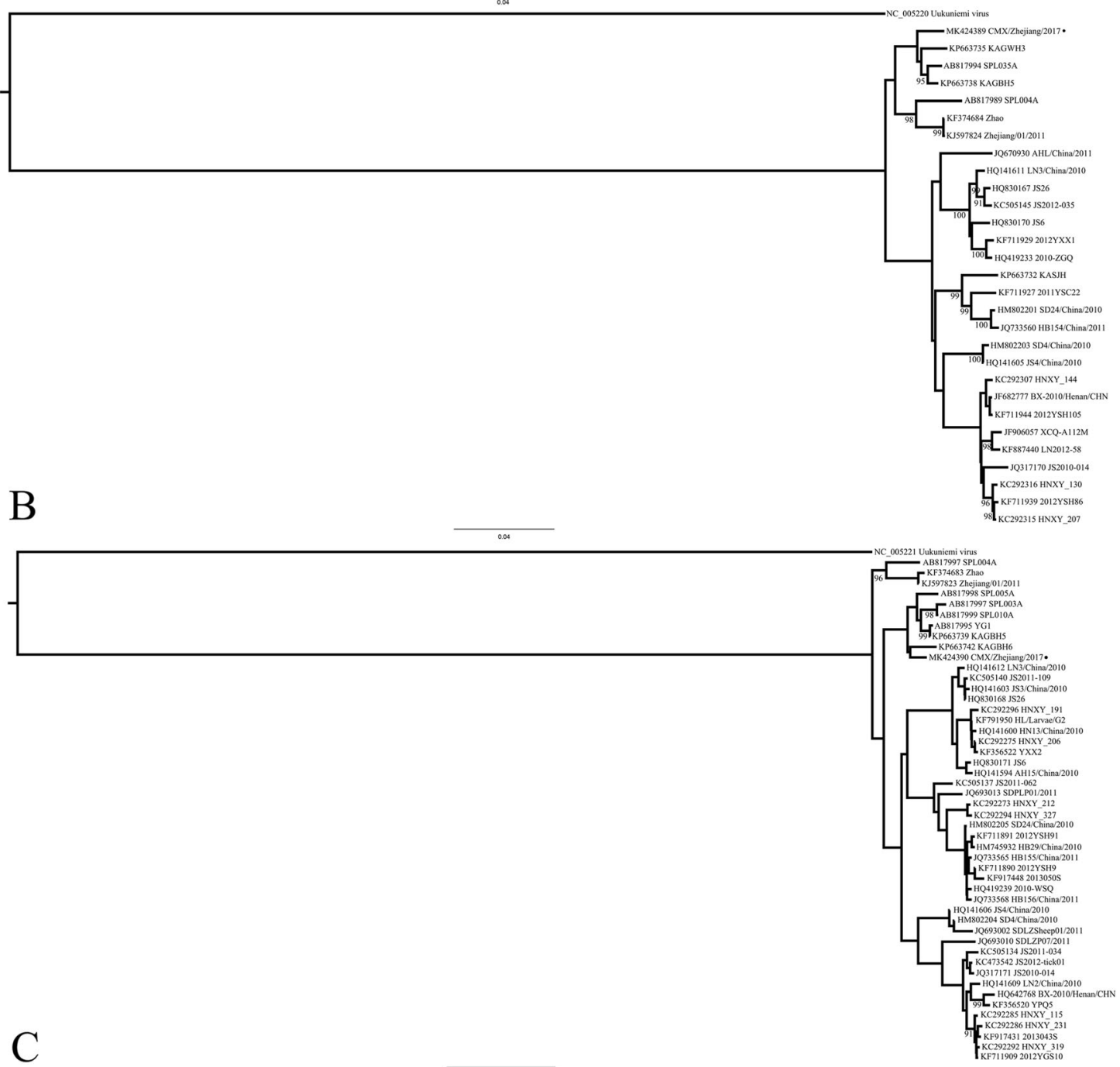

Fig. 1 Maximum likelihood trees of sequences of the virus isolated from the patient. Bootstrap values above 90 are indicated at the corresponding nodes. Segments from isolate CMX/2017/Zhejiang are highlighted with circles on each tree. $\mathbf{a} L$ segment; $\mathbf{b}$ M segment; c $\mathrm{S}$ segment 
in Zhejiang Province [24]. Other serum surveillance studies have shown that $1.0-3.8 \%$ of the examined populations in hilly regions had SFTSV antibodies, which suggests that SFTSV has circulated widely in China [22]. Although this patient denied any clear history of tick exposure, the epidemiological information indicated that the environment and its ecology are typical of those associated with SFTSV [4]. Because CNS involvement in the clinical syndrome predicts a fatal outcome, suspected cases of SFTSV infection in the local area must be monitored closely.

We have reported a patient with SFTSV infection and CNS disturbance in Dongyang, Zhejiang Province, China, in 2017. We have described the clinical, epidemiological, and pathogenic features of this case. The limitations of the study were that: 1 ) we failed to obtain a CSF sample from the patient because his SFTS progressed rapidly; 2) we collected no whole-genome information for this SFTSV isolate, which should be rectified in a future study. The long-term surveillance of cases of suspected SFTS should be undertaken in SFTSV endemic regions.

\section{Abbreviations}

ALT: Alanine aminotransferase; aPTT: Activated partial thromboplastin time; AST: Aspartate aminotransferase; CDC: Center for Disease Control and Prevention; CK: Creatine kinase; CNS: Central nervous system; CSF: Cerebrospinal fluid; CT: Cycle threshold; LDH: Lactate dehydrogenase; ML: Maximum likelihood; PLT: Platelet; SFTS: Severe fever with thrombocytopenia syndrome; SFTSV: Severe fever with thrombocytopenia syndrome virus; WBC: white blood cell

\section{Acknowledgments}

Not applicable.

\section{Authors' contributions}

Prepared the first draft of this manuscript: YS, HY, WWY. Provided the clinical data: KC, ZXL. Provided the epidemiological data: BG, ALW. Provided the virological data: JHP, HYM, YJZ. Interpreted the surveillance and virological data: YS. All authors reviewed and revised the first and final drafts of this manuscript. All authors read and approved the final manuscript.

\section{Funding}

This work was supported by grants from Medical Science Platform of Zhejiang, China (2017KY290 and 2017KY035), National Natural Science Foundation of China (81672060), Health leading Talents Program of Zhejiang Province, 2018(22)

\section{Availability of data and materials}

The viral sequences from this patient (CMX/Zhejiang/2017) were deposited in GenBank (MK424388-MK424390). https://www.ncbi.nlm.nih.gov/

\section{Ethics approval}

This study was approved by the ethics committee of the Zhejiang Provincial Center for Disease Control and Prevention (ZJCDC), China. Written informed consent was obtained from the patient. All methods were carried out in accordance with the principles of the Declaration of Helsinki.

\section{Consent for publication}

Written informed consent was obtained from the patient for publication of this case report.

\section{Competing interests}

The authors declare that they have no competing interests.

\section{Author details}

1Zhejiang Provincial Center for Disease Control and Prevention, 3399 Binsheng Road, Hangzhou 310051, Zhejiang, China. Dongyang Center for Disease Control and Prevention, Dongyang, Zhejiang, China. ${ }^{3}$ Dongyang People's Hospital, Dongyang, Zhejiang, China.

Received: 21 July 2019 Accepted: 1 October 2019

Published online: 07 November 2019

\section{References}

1. Yu XJ, Liang MF, Zhang SY, Liu Y, Li JD, Sun YL, et al. Fever with thrombocytopenia associated with a novel bunyavirus in China. N Engl J Med. 2011;364:1523-32.

2. Kim KH, Yi J, Kim G, Choi SJ, Jun KI, Kim NH, et al. Sever fever with thrombocytopenia syndrome, South Korea, 2012. Emerg Infect Dis. 2013;19: 1892-4

3. Lei XY, Liu MM, Yu XJ. Sever fever with thrombocytopenia syndrome and its pathogen SFTSV. Microbes Infect. 2015;17:149-54.

4. Sun JM, Chai CL, Lv HK, Lin JF, Wang CW, Chen EF, et al. Epidemiological characteristics of sever fever with thrombocytopenia syndrome in Zhejiang Province. China Int J Infect Dis. 2014;25:180-5.

5. Liu W, Lu QB, Cui N, Li H, Wang LY, Liu MK, et al. Case-fatality ratio and effectiveness of ribavirin therapy among hospitalized patients in China who had sever fever with thrombocytopenia syndrome. Clin Infect Dis. 2013;57: 1292-9.

6. Cui N, Liu R, Lu QR, Wang LY, Qin SL, Yang ZD, et al. Severe fever with thrombocytopenia syndrome bunyavirus-related human encephalitis. J Inf Secur. 2015;70:52-9.

7. Kaneko M, Shikata H, Matsukage S, Maruta M, Shinomiya H, Suzuki T, et al. A patient with severe fever with thrombocytopenia syndrome and hemophagocytic lymphohistiocytosis-associated involvement of the central nervous system. J Infect Chemother. 2018;24:292-7.

8. Xie YH, Yang JT, Tan Y, Lin M, Bi FY, Wu XH, et al. Clinical features and evaluation of clinical diagnosis of viral encephalitis. Dis Surveill. 2012;27: 256-62.

9. Zhang L, Wang XY, Zhang YJ, Zhang YL, Wang HL, Wang CW, et al. Sever fever with thrombocytopenia syndrome bunyavirus (SFTSV) infections in Zhejiang Province China. Int J Infect Dis. 2012;17:e137-8.

10. Lam T, Liu W, Bowden TA, Cui N, Zhuang L, Liu K, et al. Evolutionary and molecular analysis of the emergent severe fever with thrombocytopenia syndrome virus. Epidemic. 2013:5:1-10.

11. Fu YF, Li SB, Zhang Z, Man SQ, Li XP, Zhang WH, et al. Phylogeographic analysis of severe fever with thrombocytopenia syndrome virus from Zhoushan islands China: implication for transmission across the ocean. Sci Rep. 2016:6:19563.

12. Liu JW, Zhao L, Luo LM, Liu MM, Sun Y, Su X, et al. Molecular evolution and spatial transmission of sever fever with thrombocytopenia syndrome virus based on complete genome sequences. PLoS One. 2016;11:e0151677.

13. Posada D, Crandall KA. Modeltest testing the model of DNA substitution. Bioinformatics. 1998;14:817-8.

14. Martin DP, Lemey P, Lott M, Moulton V, Posada D, Lefeuvre P. RDP3: a flexible and fast computer program for analyzing recombination. Bioinformatics. 2010;26:2462-3.

15. Shi JM, Hu S, Liu XP, Yang J, Liu D, Wu L, et al. Migration recombination and reassortment are involved in the evolution of sever fever with thrombocytopenia syndrome bunyavirus. Infect Genet Evol. 2017:47:109-17.

16. Tsuda Y, Igarashi M, Ito R, Nishio S, Shimizu K, Yoshimatsu K, et al. The amino acid at position 624 in the glycoprotein of SFTSV (severe fever with thrombocytopenia virus) plays a critical role in low-pH-dependent cell fusion activity. Biomed Res. 2017:38:89-97.

17. Gai ZT, Zhang Y, Liang MF, Jin C, Zhang S, Zhu CB, et al. Clinical progress and risk factors for death in severe fever with thrombocytopenia syndrome patients. J Infect Dis. 2012;206:1095-102.

18. Cui N, Bao XL, Yang ZD, Lu QB, Hu CY, Wang LY, et al. Clinical progression and predictors of death in patients with severe fever with thrombocytopenia syndrome in China. J Clin Virol. 2014;59:12-7.

19. Nakamura S, Azuma M, Maruhashi T, Sogabe K, Sumitani R, Uemura M, et al. Steroid pulse therapy in patients with encephalopathy associated with severe fever with thrombocytopenia syndrome. J Infect Chemother. 2018; 24:389-92. 
20. Jin C, Liang MF, Ning JY, Gu W, Jiang H, Wu W, et al. Pathogenesis of emerging severe fever with thrombocytopenia syndrome virus in C57/BL6 mouse model. Proc Natl Acad Sci U S A. 2012;109:10053-8.

21. Zhang YZ, He YW, Dai YA, Xiong Y, Zheng H, Zhou DJ, et al. Hemorrhagic fever caused by a novel Bunyavirus in China: pathogenesis and correlates of fatal outcome. Clin Infect Dis. 2012;54:527-33.

22. Liu Q, He B, Huang SY, Wei F, Zhu XQ. Severe fever with thrombocytopenia syndrome, an emerging tick-borne zoonosis. Lancet Infect Dis. 2014;14:70718.

23. Huang $X$, Liu L, Du Y, Wu W, Wang H, Su J, et al. The evolutionary history and spatiotemporal dynamics of the fever thrombocytopenia and leukocytopenia syndrome virus (FTLSV) in China. PLoS Negl Trop Dis. 2014;8:e3237.

24. Zhang L, Sun JM, Yan J, Lv HK, Chai CL, Sun Y, et al. Antibodies against sever fever with thrombocytopenia syndrome virus in healthy persons China 2013. Emerg Infect Dis. 2014;20:1355-7.

\section{Publisher's Note}

Springer Nature remains neutral with regard to jurisdictional claims in published maps and institutional affiliations.

Ready to submit your research? Choose BMC and benefit from:

- fast, convenient online submission

- thorough peer review by experienced researchers in your field

- rapid publication on acceptance

- support for research data, including large and complex data types

- gold Open Access which fosters wider collaboration and increased citations

- maximum visibility for your research: over $100 \mathrm{M}$ website views per year

At BMC, research is always in progress.

Learn more biomedcentral.com/submissions 